\title{
Hip resurfacing - are we following the guidelines?
}

This article was published in the following Dove Press journal:

Clinical Audit

30 April 2010

Number of times this article has been viewed

\section{Philip Stather \\ Ruth Davey}

Orthopaedic Department, Northampton General Hospital, Northampton, UK
Correspondence: Philip Stather Orthopaedic Department, Northampton General Hospital, Cliftonville, NNI 5BD, UK

$\mathrm{Tel}+44 I 604634700$

Email philstather@doctors.org.uk
Abstract: The National Institute for Clinical Excellence (NICE) guidelines were released in June 2002 for hip resurfacing procedures. The aim of this audit was to see if these guidelines were being followed in our department. We looked at data from the previous two years, and obtained 28 sets of notes for patients who underwent this procedure. We looked at patient demographics, consent forms, and who had performed the operations. Results showed that the majority of patients were of the recommended age (93\%), the consent forms were not adequately completed in all cases, but all of the procedures were carried out by appropriately trained consultants. In conclusion we would recommend consideration of use of a consent proforma for this procedure which would ensure that all complications are discussed with the patient.

Keywords: hip, resurfacing, audit, joint, replacement

\section{Introduction}

In June 2002, the NICE Guideline TA44 was released regarding hip resurfacing procedures. ${ }^{1}$ The guidelines state that metal-on-metal (MoM) resurfacing should be done in patients who are likely to outlive a conventional hip replacement. Activity levels should be taken into account, and the procedure should be done principally in patients aged under 65 years. It also states that MoM resurfacing should only be performed by surgeons who have received specific training in the technique, and that patients should be made aware that less is known about the medium- to long-term safety and reliability of MoM than for conventional procedures. ${ }^{1}$

The aim of this research was to audit the above guideline, looking at data from the previous two years in our department, to see if the guideline was being followed. We looked at our patient demographics to determine the age of patients undergoing the procedure, the consent forms to see if the unknown medium- to long-term complications were mentioned, and to see who had performed the operation and if they were appropriately trained.

\section{Methods}

This was a retrospective audit performed at a district general hospital with a catchment area of 360,000, looking at patients who had been coded as undergoing joint replacement surgery over the previous two years in the orthopedic department. Using a standardized proforma we then looked at the medical records, documenting the consent form, relevant operation notes, patient age, what they had consented to (including risks), and the experience of the operating surgeon. 


\section{Results}

There were 50 patients coded as having undergone joint resurfacing surgery over the previous two years in our department. This data included all possible joints. Thirty-four sets of relevant medical records were found, six of which had joint resurfacing performed on a joint other than the hip. We therefore had a final sample size of 28 patients.

The average age of patients who underwent this procedure was 55 years, with the oldest patient being 79 years. Two patients (7\%) were above the recommended age for the procedure.

Consent forms had been completed by a range of consultants, registrars, and senior house officers. They were all signed and dated, but none mentioned unknown medium- to long-term complications.

The operations were performed by four consultant orthopedic surgeons who had all received specific training in the technique, and all cases were reported to the UK National Joint Registry.

\section{Discussion}

Daniel et al have stated that the results of conventional hip replacement in young patients with osteoarthritis have not been encouraging, even with improvements in the techniques of fixation and bearing surfaces. ${ }^{2}$ Modern MoM hip resurfacing was introduced as a less invasive method of joint reconstruction. NICE Guideline TA44 was brought out to regulate this procedure, and to start a register of patients undergoing this treatment. Because of the relatively new nature of MoM resurfacing, the long-term outcomes cannot be fully determined at this time, therefore when consenting patients for the procedure, this issue should be included in the consent process.

To give informed consent, individuals should understand the purpose, process, risks, benefits, and alternatives to a proposed clinical intervention and make a free, voluntary decision about whether to participate. ${ }^{3}$ General Medical Council guidelines state that patients can give consent verbally or in writing, or they may imply consent by complying with the proposed examination or treatment. However, in cases that involve higher risk, it is important that the patient's written consent is obtained. This is so that all involved parties understand what was explained and agreed to. ${ }^{4}$ The consent

Clinical Audit

\section{Publish your work in this journal}

Clinical Audit is an international, peer-reviewed, open access journal focusing on the processes and outcomes of clinical audit in any area of healthcare. All aspects of patient care are addressed within the journal and practitioners from all disciplines are invited to submit their work. Areas covered include: Publication of audits; How an audit has changed practice; Submit your manuscript here: http://www.dovepress.com/clinical-audit-journal form is the only formal record of what was discussed between the patient and doctor, so should be as thorough as possible.

In the UK, the guidance is that consent should be taken by either a trainee who is able to perform the operation or by a consultant. ${ }^{5}$ Only surgeons who have received specific training in MoM hip resurfacing operations can perform the procedure, therefore consent should only be obtained by the consultant performing the operation.

This audit has shown that the practice of consenting patients for hip resurfacing in this department is poor. We would recommend that a hip resurfacing consent proforma be used to ensure that adequate information is given to patients, and make sure that the consultant taking consent is legally covered.

We would recommend that the consent form should contain the following potential complications: bleeding, infection, pain, scar, deep vein thrombosis, pulmonary embolism, neurovascular damage, anesthetic risks, death, leg length discrepancy, prosthesis dislocation, prosthesis loosening, prosthesis fracture, need for conversion to hip replacement, need for a redo procedure, metal reactions, and unknown medium- to long-term complications. ${ }^{1,6-9}$

\section{Disclosures}

The authors declare no conflict of interest in this work.

\section{References}

1. NICE Guideline TA44. 2002. Available from: http://guidance.nice.org. uk/TA44. Accessed March 17, 2010.

2. Daniel J, Pynsent PB, McMinn DJW. Metal-on-metal resurfacing of the hip in patients under the age of 55 years with osteoarthritis. J Bone Joint Surg Br. 2004;86(2):177-184.

3. Jefford M, Moore R. Improvement of informed consent and the quality of consent. Lancet Oncol. 2008;9(5):485-493.

4. General Medical Council. Consent Guidance: Patients and doctors making decisions together. 2008. Available from: www.gmcuk.org/guidance/ ethical_guidance/consent_guidance_index.asp. Accessed March 17, 2010.

5. Aroori S, Spence RA. Chronic pain after hernia surgery - an informed consent issue. Ulster Med J. 2007;76(3):136-140.

6. Sisak K, Villar R. Early complications of hip resurfacing arthroplasty. J Bone Joint Surg Br. 2009;91B:26.

7. Shimmin A, Bare J, Back D. Complications associated with hip resurfacing arthroplasty. Orthop Clin North Am. 2005;36(2):187-193.

8. Cambridge Orthopaedic Group patient information leaflet. Available from: www.cambridgeorthopaedicgroup.com/pdfUpload/ 1010309995223452hip_resurfacing.pdf. Accessed March 17, 2010.

9. Rector J. Birmingham hip resurfacing arthroplasty consent form. Available at: http://www.boulderorthopedics.com/Portals/294/Skins/BOU/ pdfs/Birmingham\%20Consent.pdf. Accessed March 17, 2010.

\section{Dovepress}

Practical tips on how to do audits and to avoid pitfalls; How audits have changed patient care; Calls and justifications for new audits. The manuscript management system is completely online and includes a very quick and fair peer-review system, which is all easy to use. Visit http://www.dovepress. com/testimonials.php to read real quotes from published authors. 